\title{
Molecular Characterization of Migratory Locust, Locusta Migratoria Linn. (Orthoptera: Acrididae: Oedipodinae) From Ladakh Region, India
}

\author{
Vijay Veer ${ }^{1}$, A. K. Sharma ${ }^{2}$, S. N. Tikar $^{2}$, M. J. Mendki ${ }^{2}$, V. Tyagi ${ }^{2}$, K. Chandel ${ }^{2}$ \\ and W. Selvamurthy ${ }^{3}$ \\ ${ }^{1}$ Defence Research Laboratory, Tezpur, Assam, India \\ ${ }^{2}$ Defence R \& D Establishment, Jhansi Road, Gwalior, India \\ ${ }^{3}$ Defence R \& D Organization, Head Quarter, New Delhi, India
}

Correspondence should be addressed to: A. K. Sharma; agarima2001@yahoo.com

Received 3 February 2013; Accepted 10 March 2013; Published 24 June 2013

Academic Editor: HuiYing Luo

Copyright (C) 2013 Vijay Veer, A. K. Sharma, S. N. Tikar, M. J. Mendki , V. Tyagi, K. Chandel and W. Selvamurthy. Distributed under Creative Commons CC-BY 3.0

\begin{abstract}
Outbreak of Locusta migratoria occurred in Ladakh during 2006 which was mainly responsible for devastation of large pasture land and agriculture, which seriously affected phasmina wool industry. Molecular characterization of specimens of Locusta migratoria collected from the Loma area of Ladakh (J \&K) revealed that they belong to the subspecies Locusta migratoria migratoria. Mitochondrial 16S r RNA gene sequencing showed $99 \%$ similarity with the subspecies migratoria and $98 \%$ similarity with subspecies manilensis.
\end{abstract}

Keywords: Locusta migratoria migratoria, Locusta migratoria manilensis, Locust outbreak, Ladakh, 16S r RNA gene sequencing.

\section{Introduction}

Migratory locust Locusta migratoria, belonging to a monospecific genus Locusta Linnaeus of Acrididae family is one of the most important destructive agricultural pests in the world, and its outbreaks were recorded as early in the $13^{\text {th }}$ century $\mathrm{BC}$ (Fan, 1983). It is highly migratory species and has greater distribution than any other locust or grasshopper occurring in all the temperate and tropical regions of the eastern hemisphere (Asia, Europe, Africa and Australia) and also known to occur up to $4600 \mathrm{~m}$ above sea level in the Tibet
Plateau (Guo et al., 1991). Like other locust species L. migratoria also has remarkable phase polymorphism ability involving the graded changes in their morphology, physiology and behavior with transient morphs between solitarious to gregarious phases or vice versa (Uvarov et al., 1921, 1977). Both nymphs or hoppers (immature) and adults of the migratory locust show density dependent phase polymorphism. At low density both nymphs and adults have cryptic body colouration including green, orange, brown or black and sedentary in nature and show little or no tendency to aggregate. But when

Cite this Article as: Vijay Veer, A. K. Sharma , S. N. Tikar , M. J. Mendki , V. Tyagi , K. Chandel and W. Selvamurthy. (2013), "Molecular Characterization of Migratory Locust, Locusta Migratoria Linn. (Orthoptera: Acrididae: Oedipodinae) From Ladakh Region, India," International Journal of Veterinary Medicine: Research \& Reports, Vol. 2013 (2013), Article ID 942894, DOI: 10.5171/2013.942894 
their population density increases then both nymphs and adults show strong tendency for aggregation and dispersion besides having morphological changes. Nymphs (Figure 1) march in bands on ground while adults form swarms and migrate over long distances, sometimes several hundred kilometers. Population increase to high density may take several generations.

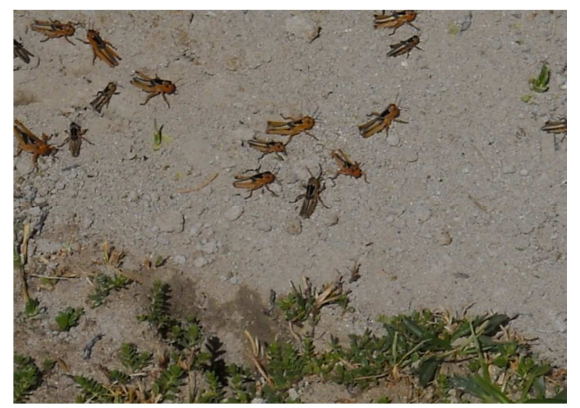

Figure 1: Nymphs of Locusta Migratoria Feeding on Pasture Grass in Loma-Dumchuk Sector, Ladakh.

Thus, due to the traits change in morphology, colouration, physiology and behaviour in the migratory locust and its wide distribution lead to recognition of different species of this single species. It caused difficulty in identification. Thus, this species was differently named as $L$. australis, L. danica, L. gallica, L. rossica, and L. solitaria. At present 7 subspecies are recognized in Locusta migratoria from various geographical regions, but the validity of the subspecies status is under considerable debate. They are L. $m$. burmana, L. m. capito, L.m. cinerascens, L. $m$. migratoria, L. m. manilensis, $L . \quad m$. migratorioides, and L. $m$. tibetensis. (http://Orthoptera.speciesFile.org Web page accessed on 24.8.2010). Thus reliable identification of a subspecies on morphology is very difficult. Zhang et al., (2009) and Zheng and Xia (1998) have studied various populations of Locusta migratoria and differentiated them into three genetically distinct groups viz. L.m.migratoria, L. m. manilensis) and L. $m$. tibetensis. Recently Ma et al., (2012) have also studied the global phylogeography and dispersal routes of the migratory locust using mitochondrial genome and shown that global populations can be divided into two different lineages, the northern lineage and southern lineage.

In 2006 an outbreak of Locusta migratoria is reported from the Ladakh region of the country which has caused serious damage to the pasture land and agriculture of the region besides terrifying people and causing traffic accidents by the swarming locusts (Kumar, 2009). Locusts' outbreak inflicted serious loss to the phasmina wool industry and animal husbandry by destroying important pasture land. This species was not reported earlier from this region. Therefore to establish the correct identification of the species we have carried out the sequence characterization of the specimens collected from the affected area (Figure 2). 


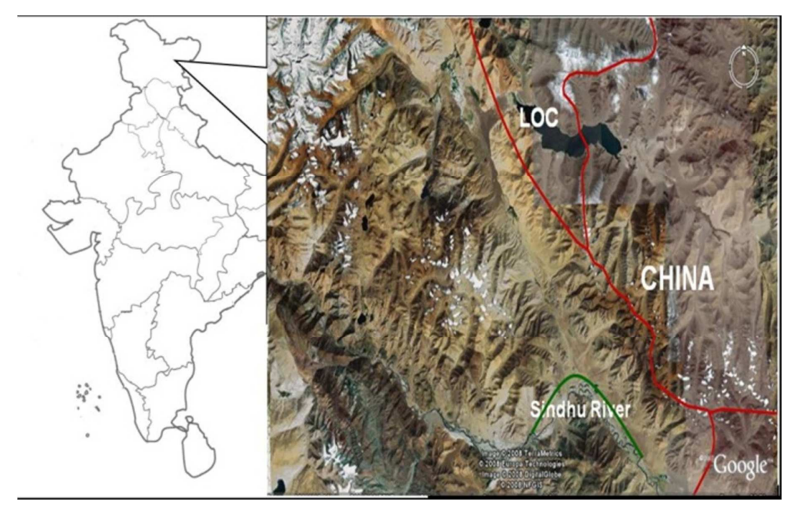

Figure 2: Locust Breeding Ground Enclosed between Green Lines along the Sindhu River in Loma -Dumchuk Sector, Ladakh. (Red Line is Line of Control (LOC) between India and China).

\section{Materials and Methods}

\section{Sample Collection}

The locust samples studied here includes the population collected from LomaDumchuk area of Ladakh region. The solitary locusts were collected during the month of September 2008. Locusts were morphologically identified as Locusta migratoria. The locust specimens were pinned and kept in the repository present in our laboratory at DRDE, Gwalior.

\section{Extraction of Locust DNA}

The DNA extraction was done by using modified Coen method (Coen et al., 1982). Each sample (single adult locust) was homogenized using motorized homogenizer (Sigma-Aldrich, USA) in the micro centrifuge tube by adding lysis buffer (all molecular grade chemicals were procured from Amresco, USA). The homogenate was immediately kept on ice for 10 minutes and followed by heat treatment at $65^{\circ} \mathrm{C}$ for 30 minutes. Subsequently, 5M potassium acetate was added and immediately transferred to ice for one hour followed by centrifugation at $13,000 \mathrm{rpm}$ for 15 minutes at $10^{\circ} \mathrm{C}$. To the supernatant obtained, a double volume of absolute chilled ethanol was added for precipitation of DNA and the tubes were kept at $-20^{\circ} \mathrm{C}$ for overnight and followed by centrifugation at $13,000 \mathrm{rpm}$ for 15 minutes at $10^{\circ} \mathrm{C}$, the precipitated DNA was washed in $70 \%$ ethanol twice. The palette DNA was allowed to air dry and finally dissolved in TE buffer. Gels were stained with ethidium bromide according to Sambrook et al., (1989) and photographed under ultra violet light using Alpha Innotech gel documentation system (Alpha Innotech, Germany) (Figure 3).

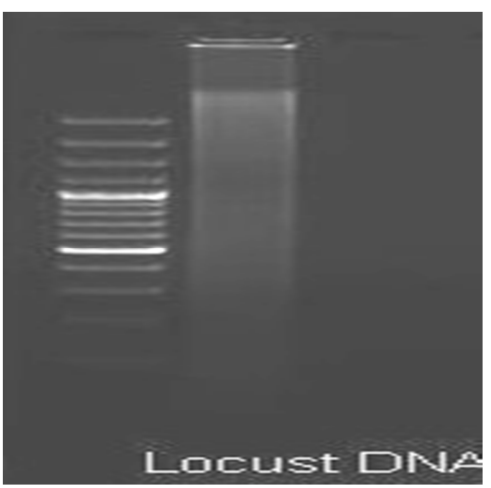

Figure 3: Genomic DNA Isolated from Locusta Migratoria. 


\section{S rRNA Gene Amplification}

The PCR was performed to amplify the $16 \mathrm{~S}$ rRNA region of mitochondrial DNA by using the following cycles in iCycler (BioRad, USA). PCR conditions were as follows: an initial denaturation of $5 \min \left(94^{\circ} \mathrm{C}\right)$ followed by 35 cycles of $1 \mathrm{~min}$ at $94^{\circ} \mathrm{C}$ (denaturation), $1 \mathrm{~min}$ at $55^{\circ} \mathrm{C}$ (Annealing), $2 \mathrm{~min}$ at $72^{\circ} \mathrm{C}$ (Extension), followed by a final extension step of $10 \mathrm{~min}$ at $72^{\circ} \mathrm{C}$. Each amplification step was performed in a total of $100 \mu \mathrm{l}$ of reaction mixture consisting of $50 \mathrm{mM} 10 \mathrm{X}$ PCR buffer, $2 \mathrm{mM} \mathrm{MgCl}_{2}$, and 0.2 mM dNTP, 10 pmoles of each forward and reverse primer, along with $10 \mathrm{ng}$ of the locust DNA. The 16S rRNA primers used in the experiment has following forward and reverse sequences Y1 (CGC CTG TTT ATC AAA AAC AT) and Y2 (CTC CGG TTT GAA CTC AGA TC) respectively. These primers were custom synthesized from Operon Biotechnologies, GmbH, Germany.

\section{Sequencing of the Gene Product}

The amplified PCR products were purified using PEG-NaCl method as described in Sambrook et al., (1989). The purified PCR products were directly sequenced in both directions using the primers used for DNA amplification. The sequencing of the selected fragments was performed according to the Sanger et al., 1997 in ABI 3730 automatic DNA sequencer with 48 capillary using Big Dye termination kit (Applied Biosystems Inc, USA).

\section{Data Analysis and Construction of Phylogenetic Tree}

The sequences obtained from all the samples including the laboratory samples were aligned using the ClustalW software to find the consensus sequences. The consensus sequences generated for each sample populations were aligned to obtain a single consensus sequence representing the locust population. The aligned sequences were reformatted appropriately and entered into DAMBE software for calculation of sequence divergence from pair wise matrices. For each pair wise comparison, the $t_{s}$ (Transition frequency) and $t_{v}$ (Transversion frequency) ratio was calculated. The uncorrected sequence divergence (p-distance), and several corrected divergence estimates, including the Jukes and Cantor (1969), Kimura two parameter (1980), Tajima and Nie (1984) and Timura and Nei (1993) models were also determined. These sequences were further evaluated for assessment of genetic diversity and construction of phylogenetic tree using Data Analysis in Molecular Biology and Evolution (DAMBE) (Xia and Xie, 2001) software. For the cluster analysis Neighbor-Joining (NJ) method, PoissonP coefficient of correlation was used to develop the phylogenetic tree. The input order is randomized with appropriate bootstrap value $(1000$ set of Data).

\section{Results and Discussion}

\section{Nucleotide Composition and Frequency Distribution}

The 16S rRNA PCR amplification resulted in about $550 \mathrm{bp}$ amplicon, the nucleotide frequency distribution for $\mathrm{A}$ is $38.71 \%$ and for $\mathrm{T} 32.26 \%$ whereas for $\mathrm{C}$ and $\mathrm{G}$ are $16.85 \%$ and $11.83 \%$ respectively (Table 1 ).

Table 1: Details of Frequency Distribution

\begin{tabular}{|c|c|c|c|c|}
\hline Sequence Name & $\mathbf{A}$ & $\mathbf{C}$ & $\mathbf{G}$ & $\mathbf{T}$ \\
\hline $\begin{array}{l}\text { 100426-R3_E13_C4-2-E8.ab1 } \\
\text { (Accession Number- JQ 026101) }\end{array}$ & 0.3871 & 0.1685 & 0.1219 & 0.3226 \\
\hline gi|161172424|gb|EU287446.1 & 0.3871 & 0.1685 & 0.1183 & 0.3226 \\
\hline $\begin{array}{l}\text { 100426-R3_C13_C2-1-E8.ab1 } \\
\text { (Accession Number-JQ 026100) }\end{array}$ & 0.3907 & 0.1685 & 0.1183 & 0.3226 \\
\hline gi|38325861|gb|AY318880.1 & 0.3871 & 0.1685 & 0.1183 & 0.3226 \\
\hline gi|27463929|gb|AF514505.1 & 0.3908 & 0.1725 & 0.1162 & 0.3204 \\
\hline gi|61971027|gb|AY856117.1 & 0.3077 & 0.0909 & 0.1573 & 0.4441 \\
\hline gi|2664352|emb|Z93294.1 & 0.3110 & 0.0748 & 0.1614 & 0.4528 \\
\hline
\end{tabular}




\section{Sequence Homology}

The 16S rRNA gene sequences were subjected to alignment with the published ones in Pubmed using NCBI-BLAST (www.ncbi.nlm.nih.gov/blast), all the sequences were found to match with the available database sequences of Locust which includes Locusta migratoria migratoria, Locusta migratoria manilensis and other locust species sequences in the GeneBank (Table 2, Figure 4). The new sequences discussed in this paper are also submitted to the GeneBank with the accession numbers as JQ 026100 and JQ026101.

Table 2: Distance Matrix Developed Using DAMBE Using UPGMA Clustering Method

\begin{tabular}{|llllll|l|}
\hline Loma-Dumchuk & & & & & \\
\hline Locusta migratoria migratoria & 3.16228 & & & & \\
\hline Loma- Dumchuk-Ladakh & 2.82843 & 1.41421 & & & \\
\hline Locusta sps. & 3.16228 & $\mathbf{0 . 0 0 0 0 0}$ & 1.41421 & & \\
\hline Locusta migratoria & 6.78233 & 6.00000 & 5.83095 & 6.00000 & \\
\hline Locusta migratoria manilensis & 27.49545 & 27.67671 & 27.74887 & 27.67671 & 27.38613 \\
\hline $\begin{array}{l}\text { Locusta migratoria } \\
\text { 30.75711 }\end{array}$ & 31.62278 & 31.81195 & 31.87475 & 31.81195 & 31.46427 \\
\hline
\end{tabular}

$\begin{array}{lllllll}1 & 2 & 3 & 4 & 5 & 6 & 7\end{array}$

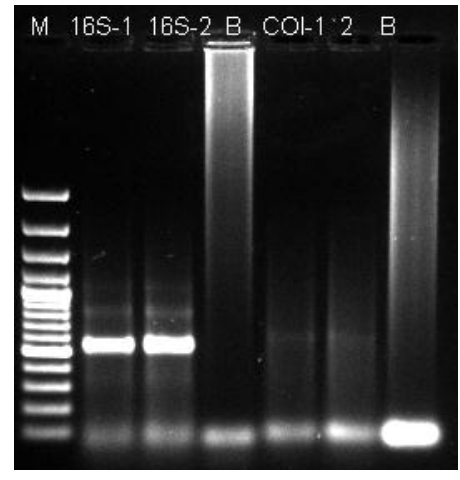

Figure 4: PCR Product of 16S rRNA Gene from Locusta Migratoria.

(Lane 1: DNA Molecular Wt Marker; Lane 2 \& 3: 16S rRNA Gene; Lane 4: Blank; Lane 5 \& 6 COI; Lane 7: Blank)

\section{Comparison of Transition and Transversion Frequency}

Comparison of transition and transversion frequencies revealed that the frequency of transversion was lower in comparison to that of transition. In case of transitions it was observed that identical transitional frequency is significantly higher than the un-identical transitions. For the test of substitution saturation (Xia et al., 2003) to test whether the observed Iss (Index for saturation substitution) is significantly less than Iss.c, from our analysis; it is found that the observed Iss (0.3040) is less than the Iss.c (0.7183).

\section{Distance Matrix and Phylogenetic Tree} Analysis

The distance matrix evolved from the sequences using the DAMBE is shown in Table 2. The minimum genetic distance of 1.41421 was observed between the Ladakh populations of locust to the L. migratoria migratoria species. The highest distance was observed between the Ladakh populations to the L. migratoria and $L$. migratoria manilensis of 31.87 and 27.74 respectively. 
The phylogenetic analysis based on the consensus tree generated, the 16S rRNA haplotypes indicate that the populations of Locust collected from Ladakh is close to the L. migratoria migratoria and other locust species whereas it is distantly placed in comparison to L. migratoria manilensis.

Though the species Locusta migratoria can be distinguished by having body size 43-56 $\mathrm{mm}$ long in female and 36-46 $\mathrm{mm}$ long in male, dark colour of inner surface of the hind femur with yellow distal band, mottled forewings (tegmina), hairy chest and absence of prosternum tag on the throat, shape of eyes and head but identification of its subspecies is difficult due to variation in the state of morphological characters even within a population. This species shows high phenotypic plasticity and have various forms; as it has phase polymorphism, egg diapause, cold-hardiness and ability for local habitat adaptation. Because of these differences, at least 7 subspecies are currently recognised, based on geographical regions and biometrical features. Recently, Ma et al., (2012) have also studied the global phylogeography and dispersal routes of the migratory locust

using mitochondrial genome such studies were also carried out by Zhang et al., (2009) have differentiated L. migratoria populations of China into three genetically distinct groups representing three subspecies namely, L. m. migratoria, L. $m$. manilensis and L. m. tibetensis which are reported from there (Zheng and Xia, 1998). It is contrary to the belief that L. migratoria being highly migratory in nature expected to have little polymorphism/heterogeneity because of strong gene flow in the populations which homogenising variations and counteracting the random drift, selection and mutations. As such no subspecies/different populations reported in another important migratory species, Schistocerca gregaria (Foskal) commonly known as desert locust. This study showed that L. migratoria has genetic polymophism and its subspecies can be distinguished with the help of genetic markers in addition to the morphological characters.

Results of sequence study of mitrochondrial 16S rRNA gene of the specimens of Locusta migratoria from Ladakh region has showed 99\% sequence similarity with subspecies L. m. migratoria in Northern China, and in the adjoining parts of Europe, and shown 98\% similarity with subspecies L. m. manilensis distributed in the East China as shown in phylogram (Figure 5). Now the migratory locust, L. m. migratoria has established itself and expanding in the Ladakh region as the outbreaks of its small swarms have occurred in the year 2007 and 2008, therefore suitable control measures are required to contain its further invasion into the warmer adjoining area of J\&K and Himachal Pradesh where it can destroy rich crops.

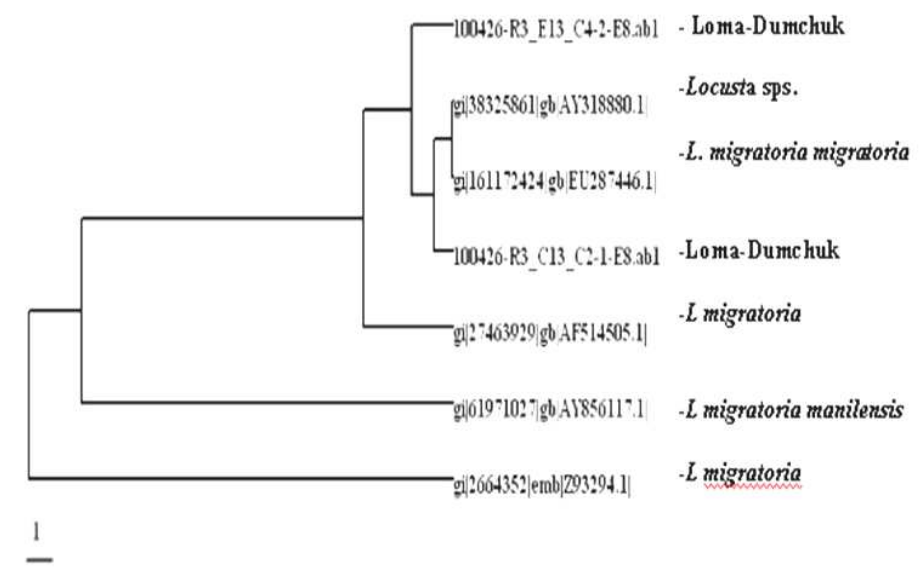

Figure 5: Phylogenetic Tree Generated by Using DAMBE 


\section{Acknowledgement}

The authors are thankful to the Director General Armed forces Medical Services, Integrated HQ of MoD (Army), New Delhi for permission to visit forward areas in Ladakh and for providing logistic facilities to the scientists.

\section{References}

Coen, E. S., Stracha, T. \& Dover, G. (1982). "Dynamics of Concerted Evolution of Ribosomal DNA and Histone Gene Families in the Melanogaster Species Subgroup of Drosophila," Journal of Molecular Biology, 158, 7-35.

Fan, Y. Z. (1983). 'Locust Outbreaks in the Shang Dynasty,' Agricultural Archaeology, 2, 314-317.

Guo, F., Chen, Y. L. \& Lu, B. L. (1991). 'The Biology of the Migratory Locusts in China,' Jinan, China, Shandong Science and Technology Press.

Jukes, T. H. \& Cantor, C. R. (1969). 'Evolution of Protein Molecules. In Mammalian Protein Metabolism (Ed Munro, H.N.),' Academic Press. New York, Pp. 21-132.

Kimura, M. (1980). "A Simple Method for Estimating Evolutionary Rate of Base Substitutions through Comparative Studies of Nucleotide Sequences," Journal of Molecular Evolution, 16, 111-120.

Kumar, R., Khan, Z. H. \& Ramamurthy, V. V. (2009). 'Tropical Outbreak of Migratory Locust, Locusta Migratoria Migratoriodes (Reiche \& Fairmaire) in Ladakh Valley of J \& K,' Biological Forum- An International Journal, 1(1), 89-97.
Ma, C., Yang, P., Jiang, F., Chapuis, M. P., Shali, Y., Sword, G. A. \& Kang, L. (2012). "Mitochondrial Genomes Reveal the Global Phylogeography and Dispersal Roots of the Migratory Locust," Molecular Ecology, 21(17), 4344-58.

Sambrook, J., Fritsch, E. F. \& Maniats, T. (1989). 'Molecular Cloning: A Laboratory Manual,' $2^{\text {nd }}$ Edition. Cold Spring Harbor Laboratory, Cold Spring Harbor, NY.

Sanger, F., Nicklen, S. \& Coulson, A. R. (1997). "DNA Sequencing with Chain Terminating Inhibitors," Proceedings of National Academy of Sciences, 74, 54635467.

Tajima, F. \& Nei, M. (1984). "Estimation of Evolutionary Distance between Nucleotide Sequences," Molecular Biology Evolution, 1, 269-285.

Tamura, K. \& Nei, M. (1993). "Estimation of the Number of Nucleotide Substitutions in the Control Region of Mitochondrial DNA in Humans and Chimpanzees," Molecular Biology Evolution, 10, 512-526.

Uvarov, B. (1977). Grasshoppers and Locusts Vol. 2. Centre for Overseas Pest Research, London, $475 \mathrm{Pp}$.

Uvarov, B. P. (1921). "A Revision of the Genus Locusta L. (=Pachytylus Fieb.), with a New Theory as to the Periodicity and Migrations of Locusts," Bulletin of Entomology Research, 12, 135-163.

Xia, X. \& Xie, Z. (2001). "DAMBE: Data Analysis in Molecular Biology and Evolution," Journal of Heredity, 92, 371373. 
Xia, X., Xie, Z., Salemi, M., Chen, L. \& Wang, Y. (2003). "An Index of Substitution Saturation and Its Application," Molecular Phylogenetics \&. Evolution, 26, 1-7.

Zhang, D. X., Yan, L. N., Ji, Y. J., Hewitt, G. M. \& Huang, Z. S. (2009). "Unexpected Relationships of Sub Structured Populations in Chinese Locusta Migratoria," BMC Evolutionary Biology, 9, 144.

Zheng, Z. M. \& Xia, K. L. (1998). 'Fauna Sinica,' Insecta Vol $10 . \quad$ Orthoptera. Acridoidea: Oedipodidae and Arcypteridae. Science Press, Beijing. 